This item was submitted to Loughborough's Research Repository by the author.

Items in Figshare are protected by copyright, with all rights reserved, unless otherwise indicated.

\title{
On the miniaturization of microstrip line-fed slot antenna using various slots
}

PLEASE CITE THE PUBLISHED VERSION

http://dx.doi.org/10.1109/LAPC.2011.6114015

PUBLISHER

Loughborough University (@ IEEE)

VERSION

AM (Accepted Manuscript)

LICENCE

CC BY-NC-ND 4.0

REPOSITORY RECORD

Al-Nuaimi, M.K.T., and W.G. Whittow. 2019. "On the Miniaturization of Microstrip Line-fed Slot Antenna Using Various Slots”. figshare. https://hdl.handle.net/2134/9987. 
This item was submitted to Loughborough's Institutional Repository (https://dspace.lboro.ac.uk/) by the author and is made available under the following Creative Commons Licence conditions.

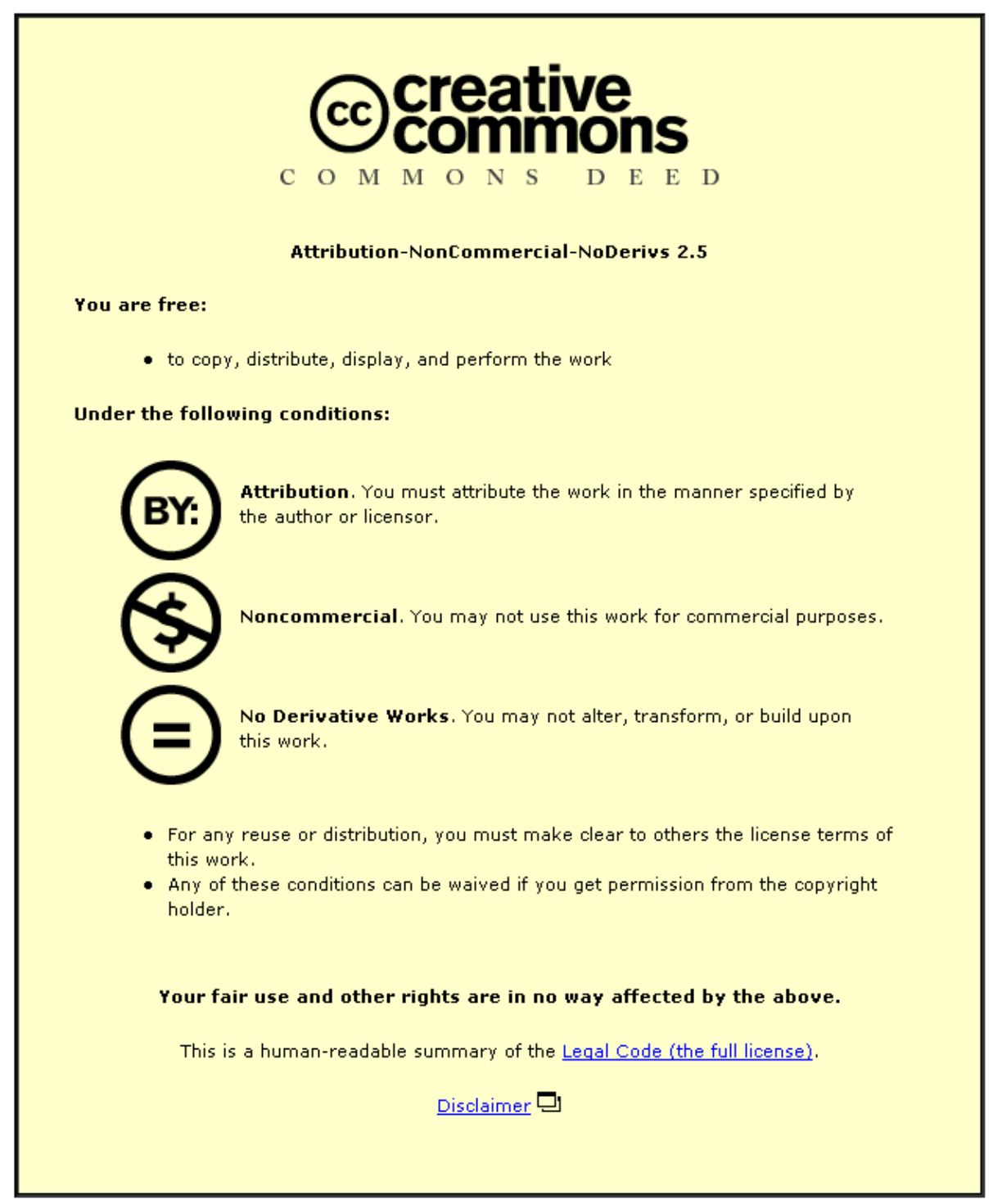

For the full text of this licence, please go to: http://creativecommons.org/licenses/by-nc-nd/2.5/ 


\title{
On The Miniaturization of Microstrip Line-Fed Slot Antenna Using Various Slots
}

\author{
Mustafa K. Taher Al-Nuaimi ${ }^{\# 1}$ and William G. Whittow ${ }^{* 2}$ \\ ${ }^{\#}$ P. O. Box 55505, Baghdad, IRAQ \\ ${ }^{1}$ Email: mustafa.engineer@yahoo.com \\ *Department of Electronic and Electrical Engineering, Loughborough University \\ Loughborough, LE11 3TU, UK \\ ${ }^{2}$ Email:w.g.whittow@lboro.ac.uk
}

\begin{abstract}
- with the advancement in microelectronic technology, there is a growing tendency in the hardware of the wireless communication systems to be smaller in size with much more functionalities. Along with this miniaturized RF systems and components, the size of the antenna becomes one of the largest and cumbersome system components. As a result, small size, light weight, low profile and power efficient antennas are in great demand. In this paper the study of the effect of various geometrical slots in the ground plane of a $50 \Omega$ microstrip transmission line fed slot antenna for compact operation is presented. The study includes four different types of ground plane slots: (a) conventional rectangular slot, (b) square dumbbell slot, (c) circular dumbbell slot and (d) double cross slot. It was found that using the square dumbbell slot resulted in $31 \%$ reduction in the antenna size compared to the conventional slot antenna. Numerical simulations are carried out using CST microwave studio based on the finite integration time-domain technique. Additional simulations were carried out using EMPIRE $\mathrm{XCcel}^{\mathrm{TM}}$ finite-difference time-domain (FDTD) software.
\end{abstract}

\section{INTRODUCTION}

Due to the growing of wireless communication market, future communication systems are expected to provide multimedia, high data rate as well as communication services. Many applications such as; imaging, vehicular radar, communications and measurement systems require integrated antennas of small size, low cost and low profile. A microstrip antenna has been considered so far as a promising candidate due to some advantages over conventional antennas, such as being low-profile, compact, low cost and ease of integration with other active components $[1,2]$.

In the recent decade, slot antennas have again become the subject of great interest to the antenna engineers as integrated planar antennas due to their miniaturization potential, relatively wide bandwidth and ease of fabrication which is basically required in many recent applications [3]. Many special situations require a rectangular slot as either an antenna or a coupling method. A narrow rectangular slot has many applications distinct from those of the conventional wire antennas, especially where low-profile or flush installations are required such as on high-speed air-craft, missiles, and satellites.

A microstrip slot antenna, one kind of the microstrip antennas, has a rectangular slot on the ground plane of a $50 \Omega$ microstrip transmission line [4]. The slot length is about half of the guided wavelength $\left(\lambda_{\mathrm{g}} / 2\right)$ in the slot line, so the slot occupies a large area on the dielectric substrate. To get around this problem, we propose a new type of the small size slot antennas.

Several slot antennas are reported to achieve improved performances, in [5], a typical circular-ring slot antenna utilizing a strip line hybrid coupler feed-network achieves good broadband circular-polarization performance. In [6], circular polarization $(\mathrm{CP})$ radiation is achieved by introducing proper asymmetry in the ring slot structure and feeding the ring slot using a microstrip line at $45^{\circ}$ from the introduced asymmetry. An annular slot antenna has recently been reported [7]. Various other slot combinations are reported to obtain compact/broadband antennas [8,9].

Currently, recent research studies are going towards miniaturization of slot antenna [1-3]. In this paper, we present a study of the effect of various slots in the ground plane of a conventional $50 \Omega$ microstrip line for compact operation. Four different types of ground plane slots are studied and compared. The substrate used is FR4 and all the antennas are fed by $50 \Omega$ microstrip line since this helps easy integration with other microwave circuitry.

\section{Slot Antenna Design And Results}

It is well known that microstrip-fed slot antennas have the advantage of a relatively large bandwidth, good impedance matching, and capability for full integration with active or passive components. To reduce costs, the substrate was selected as FR4, which has a relative permittivity of $\varepsilon_{\mathrm{r}}=4.4$, loss tangent of 0.02 and a thickness of $h=1 \mathrm{~mm}(17 \mu \mathrm{m}$ metallisation). The ground plane is chosen to be square and its size is $30 \mathrm{~mm} \times 30 \mathrm{~mm}$.

Figure 1 shows the schematic of the conventional planar slot antenna based on the FR-4 substrate and a $50 \Omega$ microstrip feed-line used to excite the slot antenna. For the design of $50 \Omega$ microstrip feed-line to be compatible with standard 
measurement systems, the dimension of the microstrip is chosen to be $1.9 \mathrm{~mm}$ on $1 \mathrm{~mm}$ thick FR-4 substrate. Based on the simulated results, it was found that the width of the rectangular slot has negligible effects and $1 \mathrm{~mm}$ thickness was used. The length of the slot $\left(\mathrm{S}_{\mathrm{L}}\right)$ determined the frequency. The parameters upon which the antenna performance shows a medium or heavy dependence are length of the slot $\left(\mathrm{S}_{\mathrm{L}}\right)$ and microstrip line offset position. Figure 2 shows the simulated return loss curve of the conventional slot antenna against frequency. The return lose of conventional slot antenna is -36 $\mathrm{dB}$ around $6 \mathrm{GHz}$.

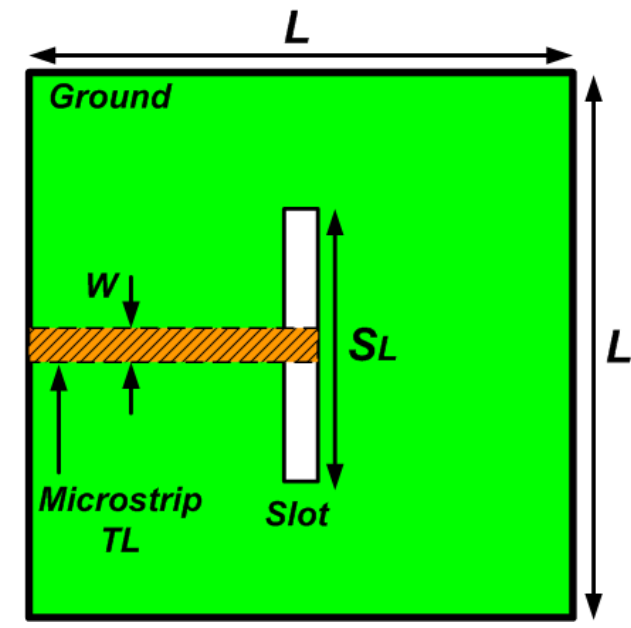

Fig. 1 The conventional microstrip fed slot antenna with $L=30 \mathrm{~mm}, W=1.9$ $\mathrm{mm}, S_{L}=15 \mathrm{~mm}$.

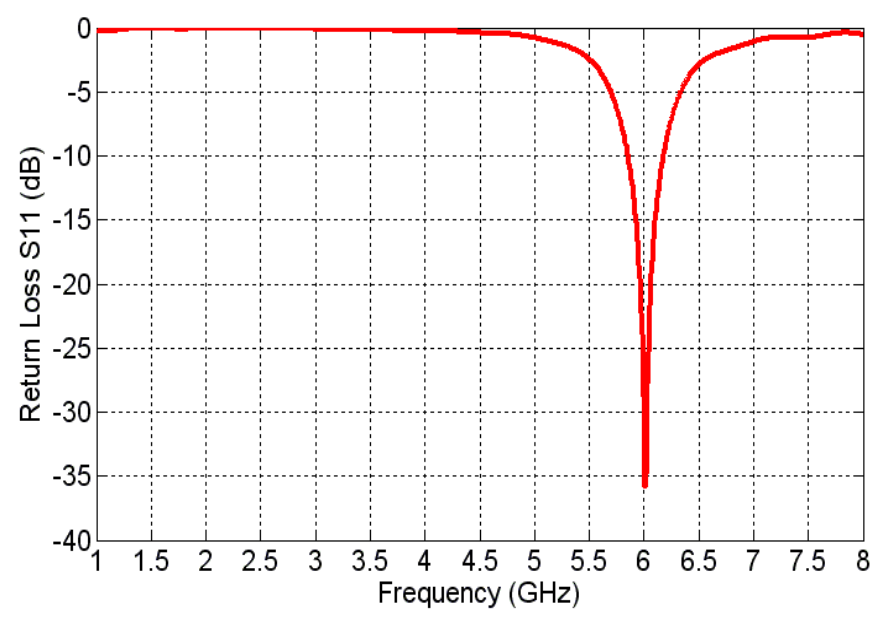

Fig. 2 Simulated return loss curve of the conventional microstrip fed slot antenna with $L=30 \mathrm{~mm}, W=1.9 \mathrm{~mm}, S_{L}=15 \mathrm{~mm}$.

To verify the effects of the proposed structures on the size reduction and antenna performances, input return losses and radiation patterns are simulated using CST Microwave studio and compared to conventional slot antenna. The proposed miniaturized slot antennas fed by a $50 \Omega$ microstrip line are shown in Fig. 3, which are printed on an FR4 substrate of thickness $1 \mathrm{~mm}$. The basic antenna structure consists of a feed line, and a ground plane with a modified slot.

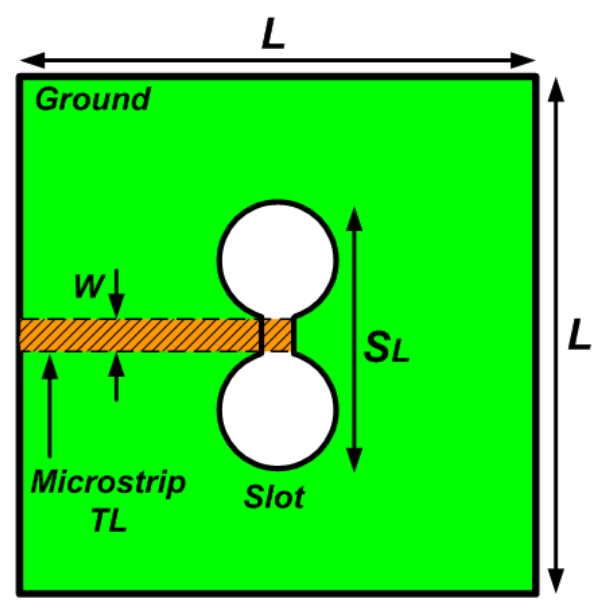

(a) Circular dumbbell slot antenna

$L$

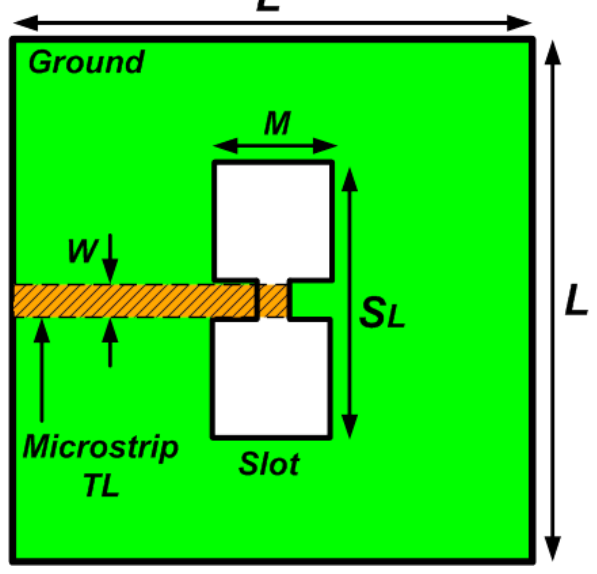

(b) Square dumbbell slot antenna

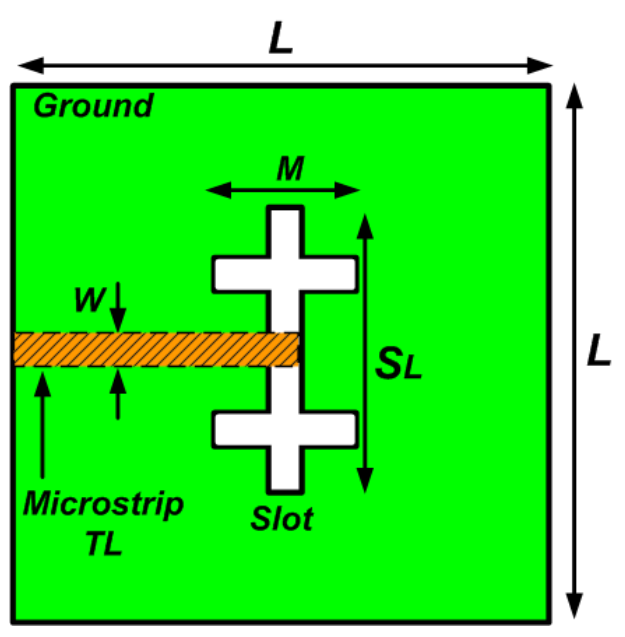

(c) Double cross slot antenna

Fig. 3 The proposed microstrip fed slot antenna with $L=30 \mathrm{~mm}, W=1.9 \mathrm{~mm}$, $S_{L}=15 \mathrm{~mm}, M=6.5 \mathrm{~mm}$.

The proposed antenna is connected to a $50 \Omega$ SMA connector for signal transmission which is considered as a 
Final author version. IEEE Loughborough Antennas \& Propagation Conference (LAPC), Loughborough, UK, 2011

wave port in CST Microwave studio. By cutting a novel slot of suitable dimensions at the ground plane, a more inductive loading effect at the edges of the slot will occur, furthermore, an increasing in the surface current path will enabling miniaturisation of the conventional slot antenna. The truncated ground plane and rectangular slots play important roles in the characteristics of the antenna, because they can adjust the electromagnetic coupling effects between the feed line and the ground plane, and improve its impedance bandwidth without any cost of size or expense.

Figure 4 shows the simulated return loss curves of the proposed miniaturized slot antennas against frequency. The length of the $50 \Omega$ microstrip feed line is adjusted to achieve an excellent input matching.

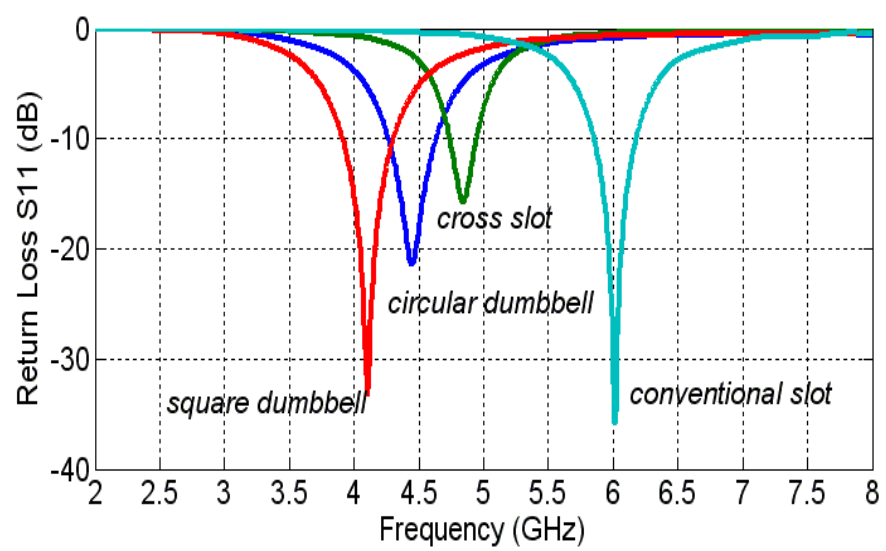

Fig. $4 \mathrm{~S}_{11}$ values of the proposed microstrip fed slot antennas.

TABLE 1

COMPARISON OF ANTENNA PERFORMANCES USING CST MWS.

\begin{tabular}{|c|c|c|c|c|}
\hline $\begin{array}{c}\text { Antenna } \\
\text { Type }\end{array}$ & $\begin{array}{c}\boldsymbol{f}_{\boldsymbol{o}} \\
(\mathbf{G H z})\end{array}$ & $\begin{array}{c}\text { BW } \\
(\mathbf{\%})\end{array}$ & $\begin{array}{c}\text { Directivity } \\
(\mathbf{d B i})\end{array}$ & $\begin{array}{c}\text { Size Reduction } \\
(\mathbf{\%})\end{array}$ \\
\hline conventional & 6.0 & 6.0 & 4.77 & - \\
\hline cross & 4.8 & 5.0 & 4.10 & 20.0 \\
\hline circular & 4.4 & 9.0 & 3.92 & 26.6 \\
\hline square & 4.1 & 9.7 & 3.76 & 31.6 \\
\hline
\end{tabular}

TABLE 2

COMPARISON OF ANTENNA PERFORMANCES USING EMPIRE XCCEL ${ }^{\text {TM FDTD }}$ SOFTWARE.

\begin{tabular}{|c|c|c|c|c|}
\hline $\begin{array}{c}\text { Antenna } \\
\text { Type }\end{array}$ & $\begin{array}{c}\boldsymbol{f}_{\boldsymbol{o}} \\
(\mathbf{G H z})\end{array}$ & $\begin{array}{c}\text { Directivity } \\
\mathbf{( d B i})\end{array}$ & $\begin{array}{c}\text { Size } \\
\text { Reduction } \\
\mathbf{( \% )}\end{array}$ & $\begin{array}{c}\text { Efficiency } \\
(\%)\end{array}$ \\
\hline conventional & 5.95 & 4.57 & - & 78.4 \\
\hline cross & 4.79 & 4.20 & 19.5 & 72.3 \\
\hline circular & 5.06 & 4.25 & 15.0 & 69.3 \\
\hline square & 4.45 & 4.10 & 25.2 & 74.4 \\
\hline
\end{tabular}

As can be seen in Fig. 4, the square dumbbell slot antenna has less resonance frequency $(4.1 \mathrm{GHz})$ compared to the

simple rectangular slot $(6 \mathrm{GHz})$. It is important to note that the resonant frequency of the proposed antenna is $1.9 \mathrm{GHz}$ lower than that of the conventional slot antenna. These results show that the proposed antenna design successfully reduced the size.

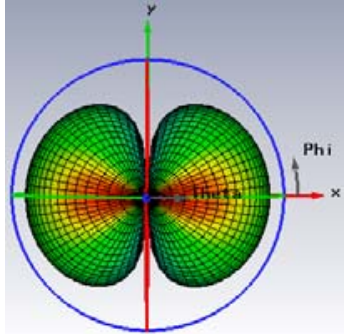

(a) $\varphi$-plane

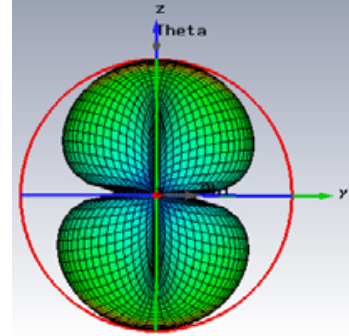

(b) $\theta$-plane

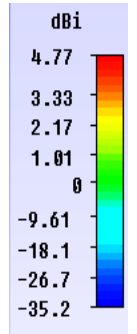

Fig. 5 Directivity pattern of the conventional slot antenna at $6 \mathrm{GHz}$.

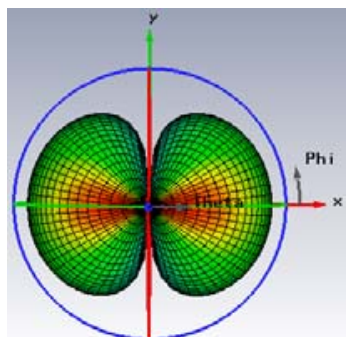

(a) $\varphi$-plane

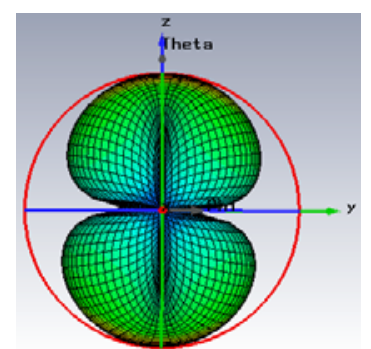

(b) $\theta$-plane

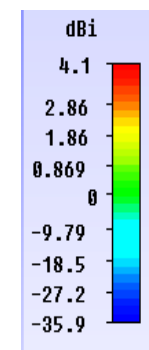

Fig. 6 Directivity plot of the cross slot antenna at $4.8 \mathrm{GHz}$.

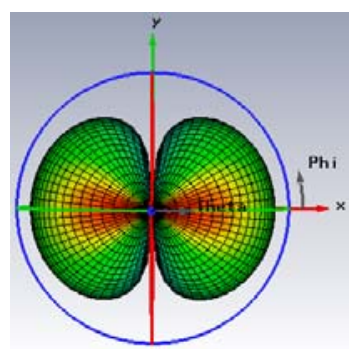

(a) $\varphi$-plane

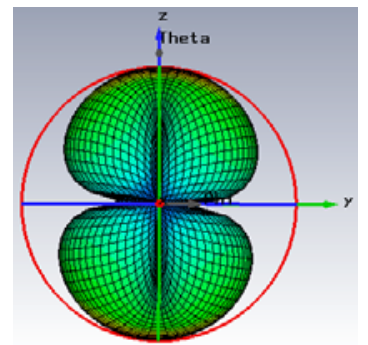

(b) $\theta$-plane

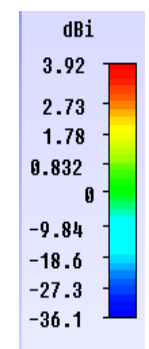

Fig. 7 Directivity pattern of the circular slot antenna at $4.4 \mathrm{GHz}$.

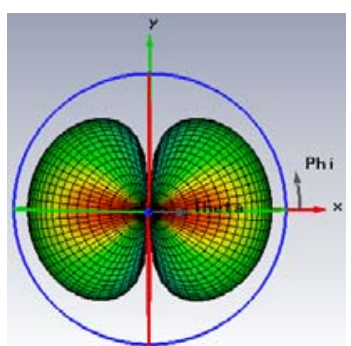

(a) $\varphi$-plane

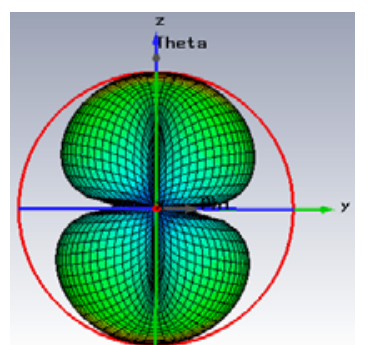

(b) $\theta$-plane

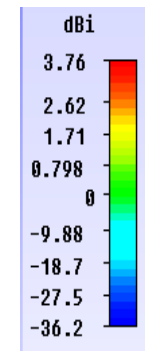

Fig. 8 Directivity pattern of the square slot antenna at $4.1 \mathrm{GHz}$.

Table 1 compares the resonant frequency, bandwidth, antenna directivity and size reduction rates of the conventional slot antenna and the proposed antennas. The size reduction values are calculated from the decrease in resonant frequency.

Table 2 shows the results using EMPIRE XCcelTM FDTD software (www.empire.de). The results with the conventional 
and cross slot antenna showed good agreement. However, the square and circular slot antennas produce a larger size reduction with CST than with EMPIRE.

The computed radiation characteristics of the proposed miniaturized slot antennas at their operating frequencies within the impedance bandwidth obtained have also been studied. Fig. 5, Fig. 6, Fig. 7 and Fig. 8 shows the directivity patterns of reference conventional slot antenna and the proposed miniaturized slot antennas at their central frequencies in $\theta$-plane and $\varphi$-plane where the antenna is placed in the $x y$-plane. The proposed antennas displays almost the same radiation characteristics as the conventional slot antenna with very clear reduction in the antenna size compared to the conventional antenna. It is observed that the radiation patterns are bi-directional and similar to those of the conventional monopole antenna.

To have a deep insight on how the use of various slots with different boundary curves will increase (change) the path of the surface current on the slotted ground plane, the distributions of surface current are simulated by using CST Microwave studio , Fig. 9. Fig.10, Fig. 11 and Fig. 12 shows both the magnitude and vector surface current distribution of each of the proposed antennas at their resonant frequencies. It can be seen that the current path in the case of dumbbell slot has the longest path among the proposed structures and compared to the conventional one.
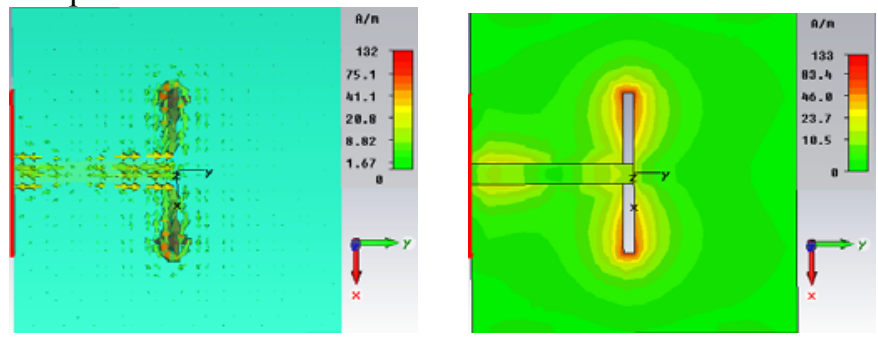

Fig. 9 (a) Vector and (b) magnitude of the Surface current distribution the Conventional slot antenna.
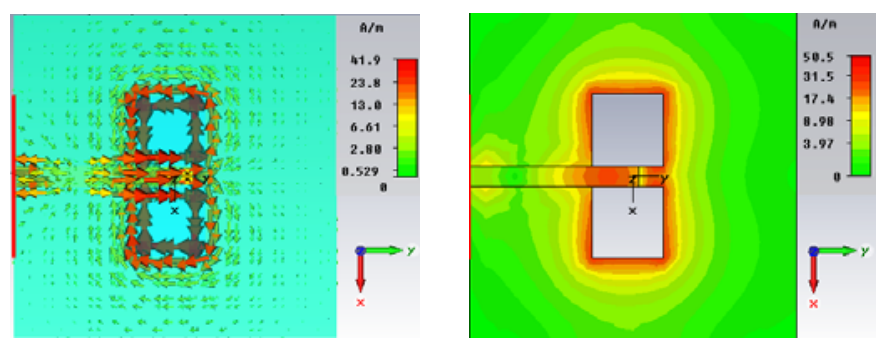

Fig. 10 (a) Vector and (b) magnitude of the Surface current distribution of the square dumbbell slot antenna.
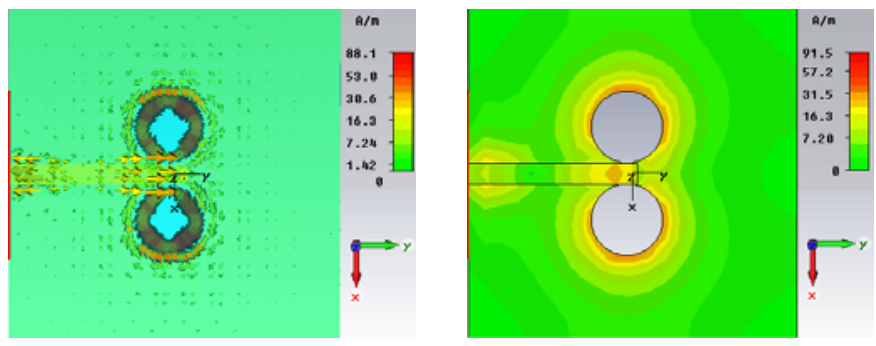

Fig. 11 (a) Vector and (b) magnitude of the Surface current distribution of the circular dumbbell slot antenna.
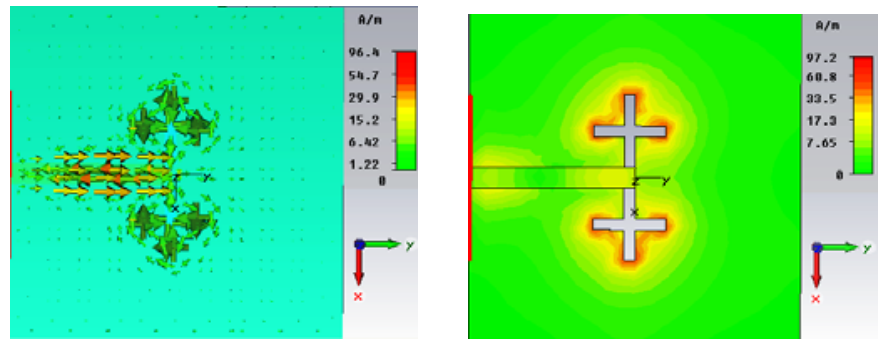

Fig. 12 (a) Vector and (b) magnitude of the Surface current distribution of the cross slot antenna.

\section{CONCLUSIONS}

In this paper the effect of different geometrical slots in the ground plane of a $50 \Omega$ microstrip line on the radiation characteristics of conventional rectangular slot antenna for compact operation is investigated. It was found that using the proposed slots gives the maximum size reduction, typically $31 \%$ reduction in size compared to the conventional slot antenna in the case of square slot antenna with the same radiation characteristics. The proposed antenna has a simple geometry and compact size and integrated on one thin substrate. Therefore, it can be fabricated incorporating easier process than other antennas. The performance of antenna can be improved further by optimizing the relative permittivity of substrate and its thickness.

\section{REFERENCES}

[1] Y. Yoshimura, "A microstrip-fed slot antenna," IEEE Trans. Microwave Theory Tech., vol. MTT-20, pp. 760-762, Nov. 1972.

[2] C. A. Balanis, "Antenna Theory Analysis and Design", Third Edition, John Wiley \& Sons 2005.

[3] J.-M. Kim, J.-G. Yook, W.-Y. Song, Y.-J. Yoon, J.-Y. Park, and H.-K. Park, "Compact meander-type slot antennas", in Proc. Antennas Propag. Int. Symp., 2001, pp. 724-727

[4] J. S. Rao and B. N. Das, "Impedance characteristics of transverse slots in the ground plane of a stripline," Inst. Elec. Eng. Proc., vol. 125, pp. 29-32, 1978.

[5] R. Azadegan, and K. Sarabandi, "A novel approach for miniaturization of slot antennas", IEEE Trans. On Antennas and Propagat., vol. 51, No. 3, March 2003, pp.

[6] T. Moselhy and H. Ghali, "Design of fractal slot antennas," 34th European Microwave Conference, EuMC2004, Oct. 12-14, 2004

[7] K. L. Wong, C.-C. Huang, and W.-S. Chen, "Printed ring slot antenna for circular polarization," IEEE Trans. On Antennas Propagat., vol. 50, pp. 75-77, January 2002.

[8] K. Hirose and H. Nakano, "Dual-loop slot antenna with simple feed," Electron. Lett., vol. 25, pp. 1218-1219, 1989.

[9] C. H. Ko, M. J. Chiang and J. Y. Sze, "Miniaturized Planar Annular Slot Antenna Design Utilizing Shorting Conducting Strip", IEEE Antennas And Wireless Propagation Letters, Vol. 8, 2009 